\title{
Enhancing Exterior Durability of Jack Pine by Photo-Stabilization of Acrylic Polyurethane Coating using Bark Extract: Part 1- Effect of UV on Color Change and ATR-FTIR Analysis
}

\author{
Sudeshna Saha1, Duygu Kocaefe ${ }^{1 *}$, Yaman Boluk ${ }^{2}$, Andre Pichette ${ }^{1}$ \\ ${ }^{1}$ Université du Québec a Chicoutimi, Canada \\ 555, boul de l’Université, Chicoutimi Québec Canada G7H 2B1 \\ * Duygu.Kocaefe@uqac.ca \\ Ph No: 1-418-5455011 (5215) \\ Fax No: 1-418-5455012 \\ ${ }^{2}$ University of Alberta, Department of Civil and Environmental Engineering, \\ 3-142 Markin/CNRL Natural Resources, Edmonton Alberta Canada T6G 2W2
}

\begin{abstract}
Heat-treated wood is a value-added product but its exposure to various environmental factors leads to discoloration of wood surface due to the photochemical reactions. Discoloration has become an important economic problem for wood industries since product specifications are now more demanding. In addition, stricter environmental legislations necessitate the development of environmentally friendly transparent coatings with minimal use of chemicals which balances aesthetic and protection. In this study, the acrylic polyurethane coating was improved with the addition of natural antioxidant (bark extract) and lignin stabilizer alone or in combination to enhance the resistance of this coating to different weathering factors. An accelerated aging test was conducted with the aim of comparing the acrylic polyurethane coatings containing different additives with the commercially available pigmented solvent borne coating used by industry and organic UV absorbers. The modifications in chemical structure of coatings were characterized by ATR-FTIR analysis. The color change data showed that the coating containing bark extract was the most effective and performed better than the industrial coating. However, the visual assessment showed that the coating containing bark extract and lignin stabilizer had the best performance. FT-IR analyses suggested that the chain scission reaction took place throughout the weathering but its effect was not significant for any of the coatings.
\end{abstract}

Key Words: Heat-treated jack pine, Acrylic polyurethane, Weathering, Bark extract, Color change, ATR-FT-IR analysis 


\section{Introduction}

Heat-treated wood is a value-added product [1-3] and has a unique place among other competitive materials such as concrete, metals and plastics due to its aesthetical appeal (attractive dark brown color), improved dimensional stability and biological resistance. Saguenay-Lac-St-Jean region of Quebec in Canada is the leader in heat treatment of wood in North America. Exposure of heat-treated wood to various environmental factors such as solar radiation, water, heat, pollutants etc. for long periods leads to photochemical reactions which result in discoloration of wood surface [4-12]. This is mainly due to the degradation of lignin (main UV absorber among the wood components) at the superficial surface of the wood by UV light leading to formation of colored hydrophilic byproducts, and its ensuing removal by rain. With the move towards the value-added products and requirement of higher product quality discolorations have become an important economic problem. In order to increase the service life of this new non toxic product, development of environmentally friendly transparent coatings with minimal use of chemicals became very important for wood industries. The main challenge of coating development is to assure the balance between aesthetic and protection.

Water based acrylic polyurethane coatings have wide applications and was chosen for this study because of their high durability characteristics in accelerated weathering environment and environmentally friendliness [13-18]. In order to block the harmful portions of solar radiation and slowdown the photodegradation of the organic substrates long lasting UV absorbers are needed to incorporate into the resin $[13,19,20]$. Similarly, HALS also stabilizes the polymeric coatings by scavenging the free radicals produced during weathering. Most of the UV stabilizers available in the market are toxic in nature. For this reason development of a non toxic UV stabilizer which can delay the discoloration of the polymeric coatings on the wood surface is of utmost importance. Bark extract can be a potential UV stabilizer due to it's highly antioxidant properties. The purpose of this study is to evaluate the effectiveness of the natural antioxidant (bark extract) with or without lignin stabilizer in delaying the photodegradation of acrylic polyurethane coating applied to heat-treated jack pine. The results are compared with the commercially available organic UV stabilizers when exposed to accelerated weathering. The color measurement results along with the visual assessments before and after weathering of these acrylic polyurethane coatings with different UV stabilizers are also compared with those of the solvent borne commercially available coating (almost green and opaque in nature) containing some toxic components used by the industry.

The coating degradation is a combination of both physical and chemical processes. The significance of FTIR in the analysis of chemical modification of polymeric materials has been recognized in recent years [13,21-26]. In this study the chemical modifications of these coatings after weathering for different time periods were evaluated by the ATR-FTIR analysis.

\section{Materials and Methods}

\subsection{Wood Surface Preparation}

In this study, commercially available jack pine wood heat-treated at $210^{\circ} \mathrm{C}$ was used for all the tests. The wooden boards with tangential surfaces were randomly chosen from the lot obtained 
from ISA industries. The wooden panels were then planed and sawed. The test panels were selected carefully avoiding knots and cracks and any other visible defects. The dimension of the wood samples used in the accelerated weathering test was $20 \mathrm{~cm} \times 7 \mathrm{~cm} \times 1.9 \mathrm{~cm}$.

\subsection{Transmission Tests}

The transmission spectra of different concentration of natural antioxidant (bark extract) were carried out using UV/VIS spectrophotometer (Agilent 8453 UV-VIS spectroscopy system). Different amount of the bark extract was dissolved in methanol.

\subsection{Preparation of Coatings}

Sunlight-cured two component acrylic-polyurethane (Bayer Corporation) coating was used for this study as the base. Organic UV stabilizers (Tinuvin123 and Tinuvin1130 obtained from CIBA specialty chemicals), organic antioxidant (bark extract, synthesized in the laboratory), and lignin stabilizer (obtained from CIBA specialty chemicals) were used as additives. Alone or different combinations of these additives were tested. The formulations of different coatings are presented in Table1.

\section{Coating Description}

Acrylic polyurethane coating

Acrylic polyurethane with organic UV absorber

Acrylic polyurethane with bark extract

Acrylic polyurethane with lignin stabilizer

Acrylic polyurethane with bark extract and lignin stabilizer

Industrial coating
The base coating without any light stabilizer

The base coating + Tinuvin123 +

Tinuvin1130 as UV stabilizer

The base coating + bark extract as UV stabilizer

The base coating + lignin stabilizer

The base coating + bark extract + lignin stabilizer

Laurentide coating

\subsection{Accelerated Weathering Test}

42 samples $(6.6 \mathrm{~cm} \times 7 \mathrm{~cm} \times 1.9 \mathrm{~cm})$ were coated with three layers except for industrial coating. For this coating only two layers are used as recommended. Seven samples were prepared for each coating. Six of these samples were exposed to accelerated weathering test and one sample for each coating was kept as a reference. The reference samples were protected from the light exposure.

Accelerated aging test was conducted in Atlas Xenon Weather-Ometer (with a daylight filter, irradiation $0.35 \mathrm{~W} / \mathrm{m}^{2}$ at $340 \mathrm{~nm}, \mathrm{BPT} 63 \pm 3^{\circ} \mathrm{C}$ and continuous light cycle with $102 \mathrm{~min}$ light and 18 min specimen spray with light). All the samples were exposed to UV light for different times. 
The maximum exposure time was $1500 \mathrm{~h}$. A sample for each coating was taken out after $72 \mathrm{~h}$, 168h, 336h, 672h, 1008h and $1500 \mathrm{~h}$ exposure.

\subsection{Color Measurement}

The color of all the samples was measured before and after the weathering test using Datacolor CHECK ${ }^{\circledR}$ spectrocolorimeter with diffuse illumination $8^{\circ}$ viewing in conformance with CIE publication No.15.2 (Colorimeter based on D65 light source by simulating day light). The CIE $L^{*}, a^{*}, b^{*}$ coordinates are characterized by three parameters. $L^{*}$ axis represents the lightness and it varies from 100 (white) to 0 (black). $a^{*}$ and $b^{*}$ are the chromaticity indices where $+a^{*}$ is the red, $-a^{*}$ is the green, $+b^{*}$ is the yellow, $-b^{*}$ is the blue directions. The color differences were calculated using the equations [1] to [3] and the total color difference was calculated from equation [4] for each sample.

$$
\begin{aligned}
& \Delta L=L_{\text {after weathering }}^{*}-L_{\text {before weathering }}^{*} \\
& \Delta a=a_{\text {after weathering }}^{*}-a_{\text {before weathering }}^{*} \\
& \Delta b=b_{\text {after weathering }}^{*}-b_{\text {before weathering }}^{*} \\
& \Delta E=\sqrt{\Delta L^{2}+\Delta a^{2}+\Delta b^{2}}
\end{aligned}
$$

\subsection{FT-IR Analysis}

The chemical modifications of the coated wood samples due to weathering were examined by FT-IR spectroscopy. IR spectra were collected in the wave number range of 550-4000 $\mathrm{cm}^{-1}$ and all the spectra were recorded at $4 \mathrm{~cm}^{-1}$ resolution. Each time 20 scans were carried out prior to the Fourier transformation. All spectra were collected using a diamond micro-ATR crystal (Jasco FT/IR 4200). The incident angle of the crystal was $47^{\circ}$ corresponding to an analysis depth of $0.2-$ $5 \mu \mathrm{m}$, depending on the wave number. This ensured that the recorded FT-IR spectra were solely for the coating and there was no interaction with wood. The diameter of the actual analysis area was $\sim 30 \mu \mathrm{m}$. All spectra were analyzed using Jasco spectra manager software.

\section{Results and Discussions}

\subsection{Transmission Tests}

In order to assess the performance of the bark extract as potential UV absorber, UV-VIS spectroscopy tests were carried out using different concentration of the bark extract.

The transmission tests results are presented in Figure1. 1\% bark extract transmittance spectrum shows that it can be used as a potential UV absorber as no transmission was observed up to 403nm (in the UV range) whereas in the visible region almost complete transparency was realized. With increase in concentration of the bark extract, there was a clear shift of the lower limit towards the red region (403nm for $1 \%$ bark extract to $482 \mathrm{~nm}$ for $15 \%$ bark extract). Since not only UV light but small wavelength of visible portion of sunlight also cause wood weathering, this bark extract at higher concentrations can be very effective in diminution of 
weathering effect on wood surface. But before drawing any conclusions, their performance should be tested.

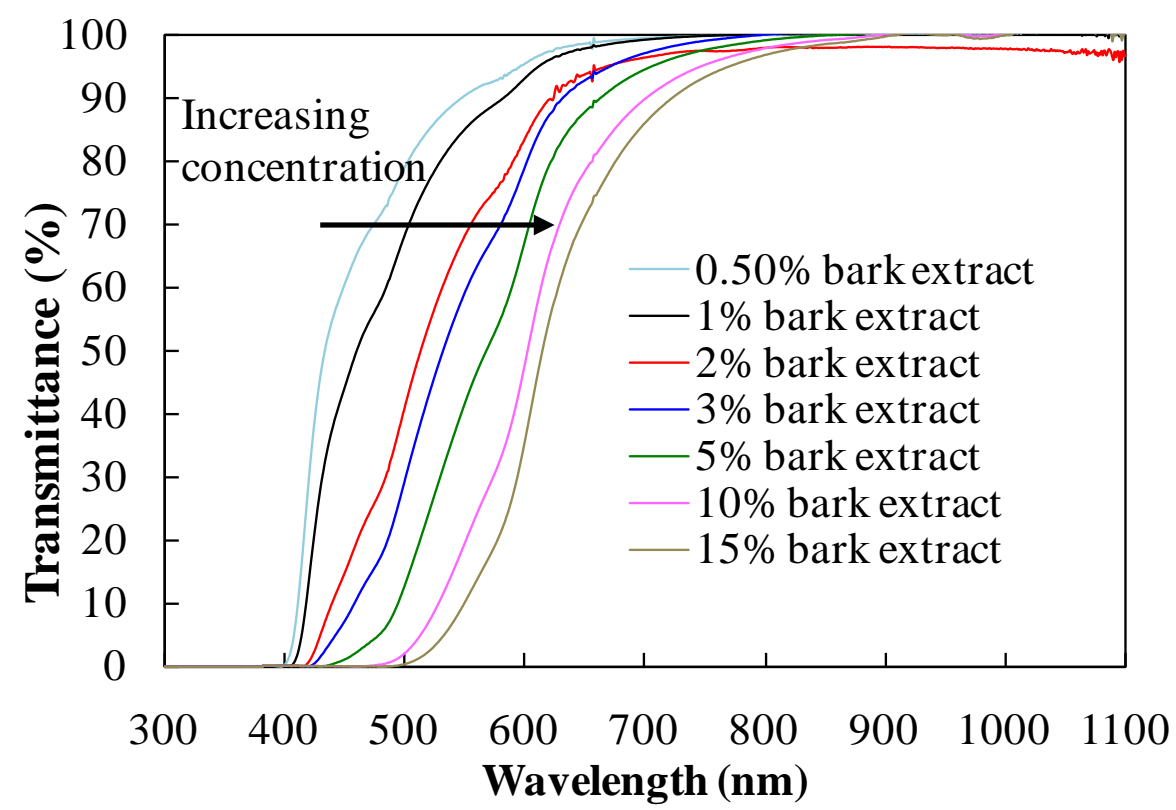

Figure 1 The transmittance spectra of different concentration of bark extract in methanol

\subsection{Color Measurement}

The accelerated weathering test was carried out in order to study the effect of UV exposure on color change of coated and heat-treated wood within a shorter time span compared to natural weathering.

The color measurement data suggested that other than industrial coating all the other coatings became greener (Figure 2(a)) with increasing weathering time whereas industrial coating became redder. The industrial coating exhibited lowest variation in red-green index while acrylic polyurethane coating containing organic UV absorber showed highest variation of the same index. The industrial coating, acrylic polyurethane coating containing bark extracts with or without lignin stabilizer demonstrated yellowish nature whereas other coatings showed bluish nature after $1500 \mathrm{~h}$ of weathering. For the former three coatings the yellow-blue index increased during the initial stages of weathering. This was followed by a decrease in the same index though extent of this change was higher for industrial coating (Figure 2(b)). The highest change in yellow-blue index was observed for base acrylic polyurethane coating, conversely, the lowest variation of the same index was observed for the acrylic polyurethane coating containing bark extracts with or without lignin stabilizer. 


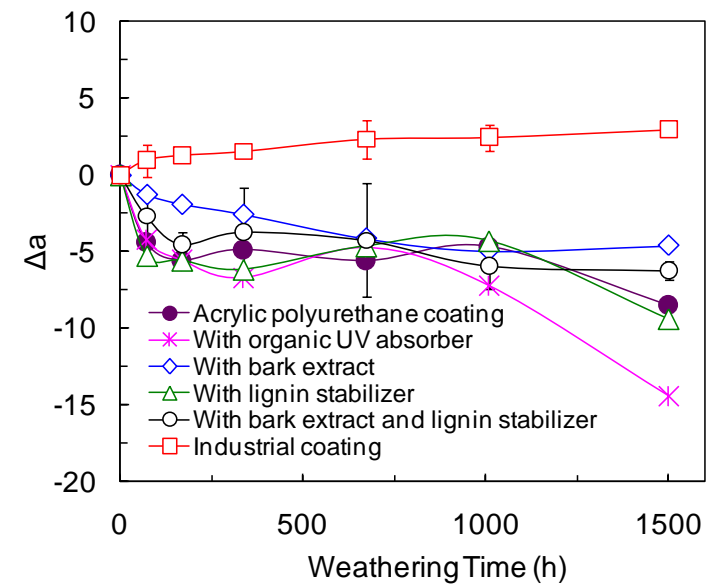

(a)

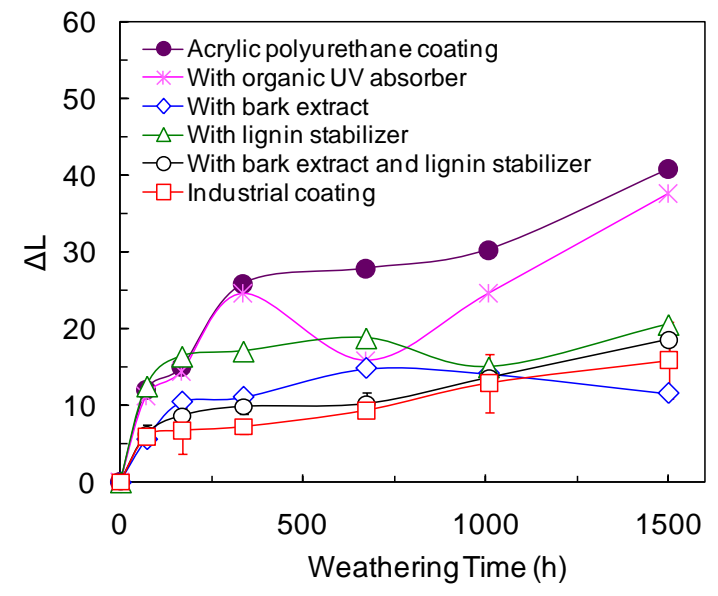

(c)

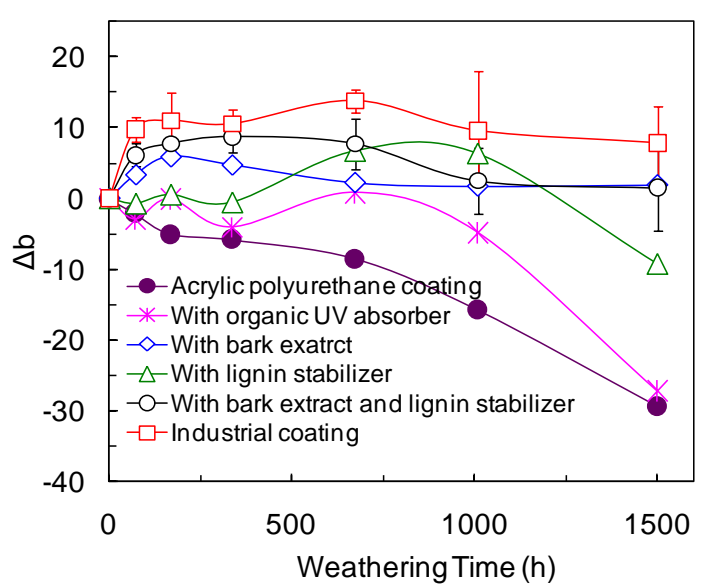

(b)

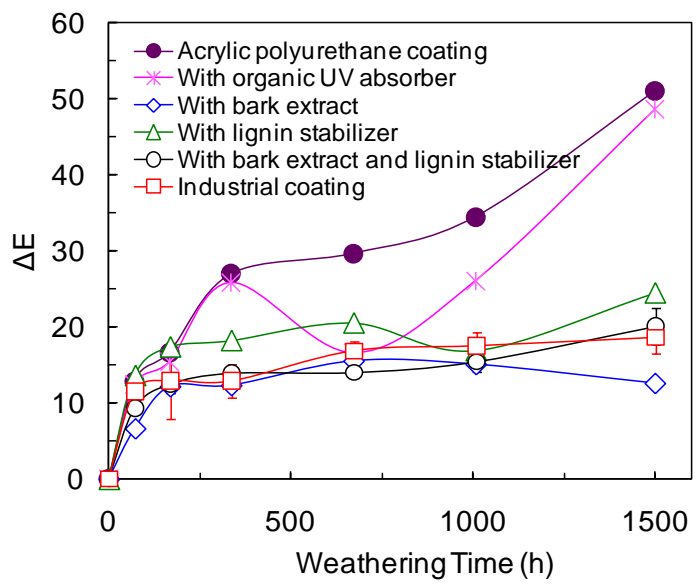

(d)

Figure 2 Comparison of base, acrylic polyurethane coatings stabilized with different additives and industrial coating (a) red-green index, (b) yellow-blue index, (c) lightness index and (d) total color change for different weathering time

The lightness of all the coatings increased with weathering time; however, lightness variation of industrial coating was lower for initial 1100h of weathering (Figure 2(c)) compared to coatings developed during this study. After $1100 \mathrm{~h}$ of weathering, the acrylic polyurethane coating containing bark extract pertained lowest lightness variation. The highest change in lightness index was observed for the base acrylic polyurethane coating. The acrylic polyurethane coating stabilized with organic UV absorbers also exhibited high lightness index change. The acrylic polyurethane coating containing lignin stabilizer showed almost similar lightness variation as the acrylic polyurethane coating containing bark extract and lignin stabilizer; however for initial period of weathering the former coating showed comparatively higher lightness variation.

Highest color change was detected for the base acrylic polyurethane coating (Figure 2(d)) nevertheless the acrylic polyurethane coating stabilized by organic UV absorbers also showed a high total color change after $1500 \mathrm{~h}$ of weathering. The acrylic polyurethane coating containing bark extract pertained highest protection (Figure 2(d)) among all coatings during the accelerated weathering test, except for $500 \mathrm{~h}$ to $1000 \mathrm{~h}$ of weathering. In this exposure periods, the acrylic polyurethane coating containing bark extract and lignin stabilizer showed highest protection. 
Similar protective characteristics were observed for the acrylic polyurethane coating containing bark extract alone or with lignin stabilizer and the industrial coating during initial $400 \mathrm{~h}$ of aging but the color of acrylic polyurethane coating containing bark extract and lignin stabilizer varied less compared to the color of the industrial coating from $400 \mathrm{~h}$ to $1400 \mathrm{~h}$ of weathering. On the other hand, the acrylic polyurethane coating with bark extract exhibited better protection throughout compared to the industrial coating. The acrylic polyurethane coating containing lignin stabilizer also showed high protective characteristic.

High UV resistance of industrial coating was expected as it is a highly pigmented (almost green and opaque) solvent based coating which tends to cover the natural grain texture of heat-treated jack pine surface completely. Also, this coating contains some toxic substances. On the other hand, the acrylic polyurethane is transparent, non toxic and waterborne coating which contains natural antioxidant with or without a very small amount of lignin stabilizer. This study showed that the bark extract and lignin stabilizer alone or together can replace effectively the pigments and UV absorbers which are used for slowing down the degradation of wood in outer environment.

\subsection{Visual Assessment}

The visual assessment is very important from end user's perspective as this is the main factor which accounts for coating's durability and time for repainting the substrate surface.

The visual assessment of different coatings on heat-treated jack pine revealed that the base acrylic polyurethane coating showed poor protective characteristics starting from the initial period of weathering and became completely white at the end of 1500h of weathering (Figure 3). On the other hand, the acrylic polyurethane coating with organic UV absorbers displayed better protection than the base coating but also underwent heavy color loss (Figure 3). Small cracks were formed on the surface after $1500 \mathrm{~h}$ of weathering for both of the above mentioned coatings. When the acrylic polyurethane coating was stabilized with bark extract, it became highly efficient in protecting the heat-treated jack pine surface from weathering. According to naked eye evaluation, almost no color change was observed for this coating with the exception of two or three local degradation points (small white patches) at the end of $1500 \mathrm{~h}$ of weathering. On the other hand acrylic polyurethane coating containing lignin stabilizer demonstrated high degradation at the edges after1008h of weathering and the coating degradation started only after $672 \mathrm{~h}$ of weathering. The acrylic polyurethane coating containing bark extract and lignin stabilizer was the most efficient coating developed during this study and no degradation was observed with naked eye for this coating even after 1500h of weathering (Figure 3). Very little color change (became slightly lighter) was detected for this coating but the color change was homogeneous. The industrial coating though covered fully the heat-treated jack pine surface, did not protect the surface completely. Local degradation started only after $672 \mathrm{~h}$ and complete degradation took place after 1500h of weathering (Figure 3). The cracks and fissures were also observed on the surface after $1008 \mathrm{~h}$ of weathering for this coating. 


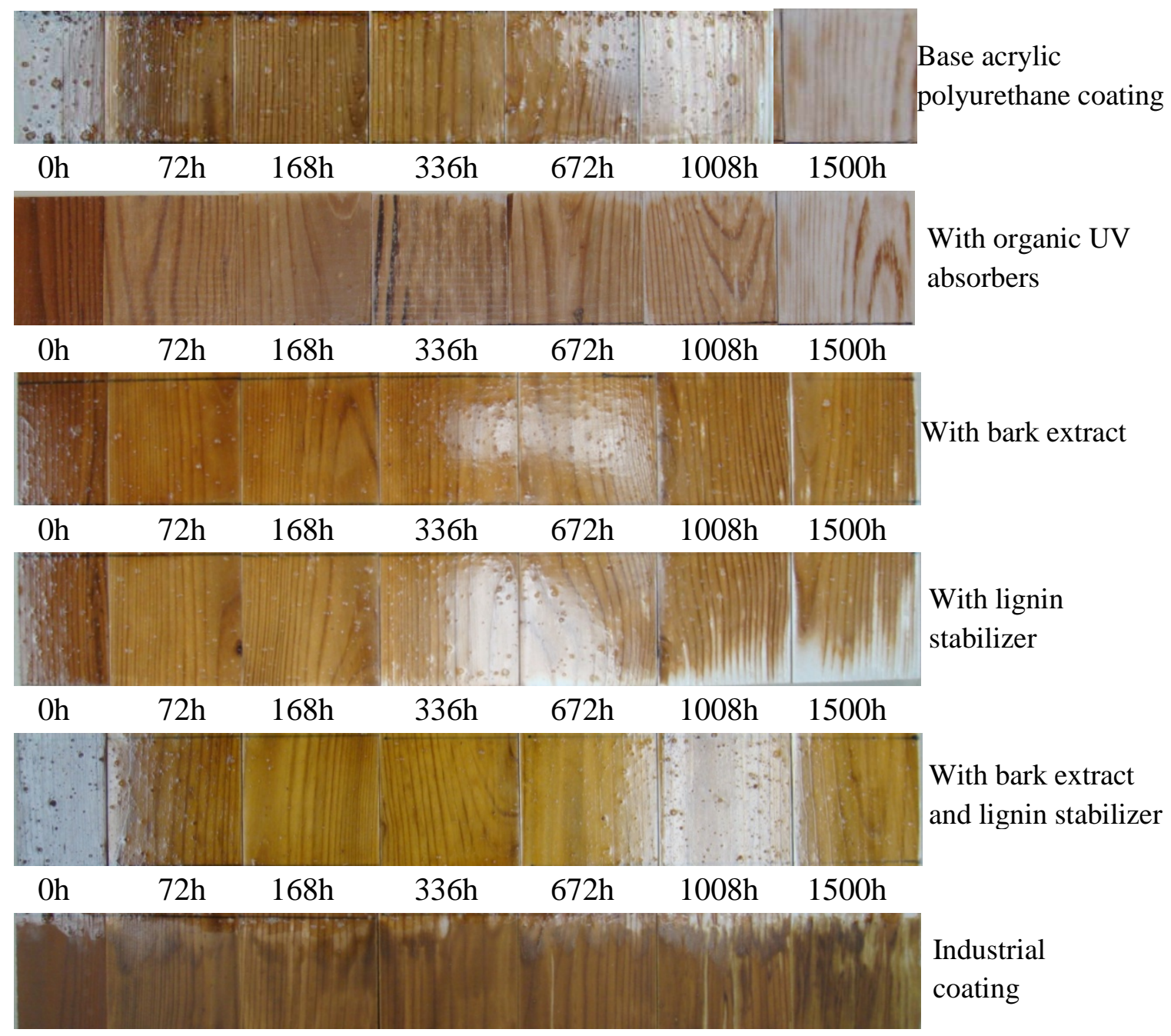

Increasing weathering time

Figure 3 Visual assessment of coated heat-treated jack pine for different weathering times

\subsection{FT-IR Analysis}

Before the weathering test, all the coated samples were cured at $23^{\circ} \mathrm{C}$ and $15 \%$ humidity (laboratory condition) for one week. The effects of different additives on chemical changes of acrylic polyurethane coatings were analyzed using ATR-FT-IR. The FT-IR spectra of the acrylic polyurethane coating containing bark extract and lignin stabilizer coated wood panels before and after weathering for different exposure times are shown in Figures 4(a) and 4(b). The assignments of the bands were performed based on the literature FT-IR data for acrylicpolyurethane system that is well documented [13, 21-27]. 


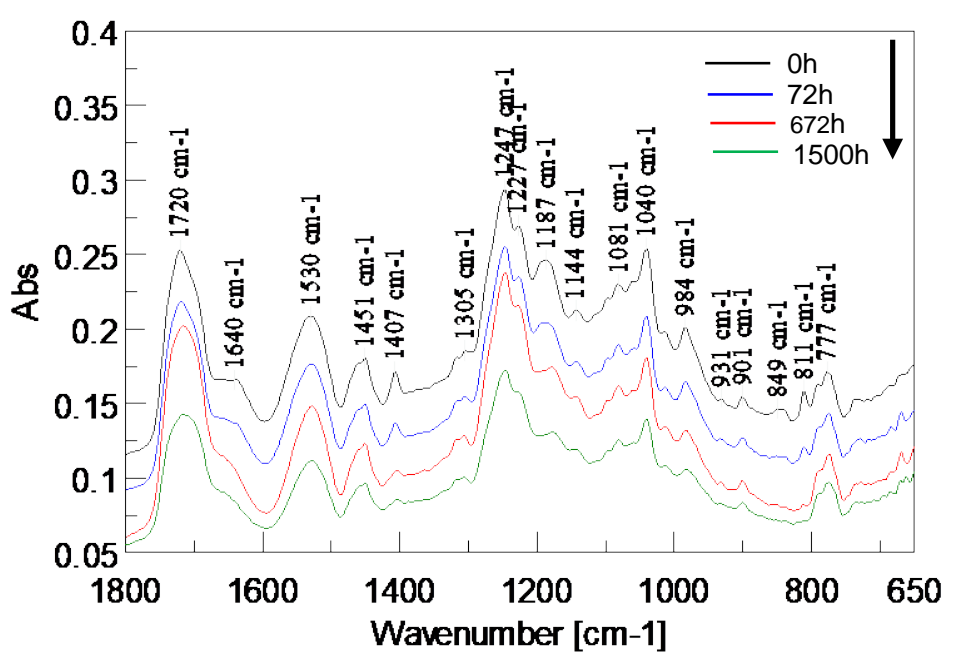

(a)

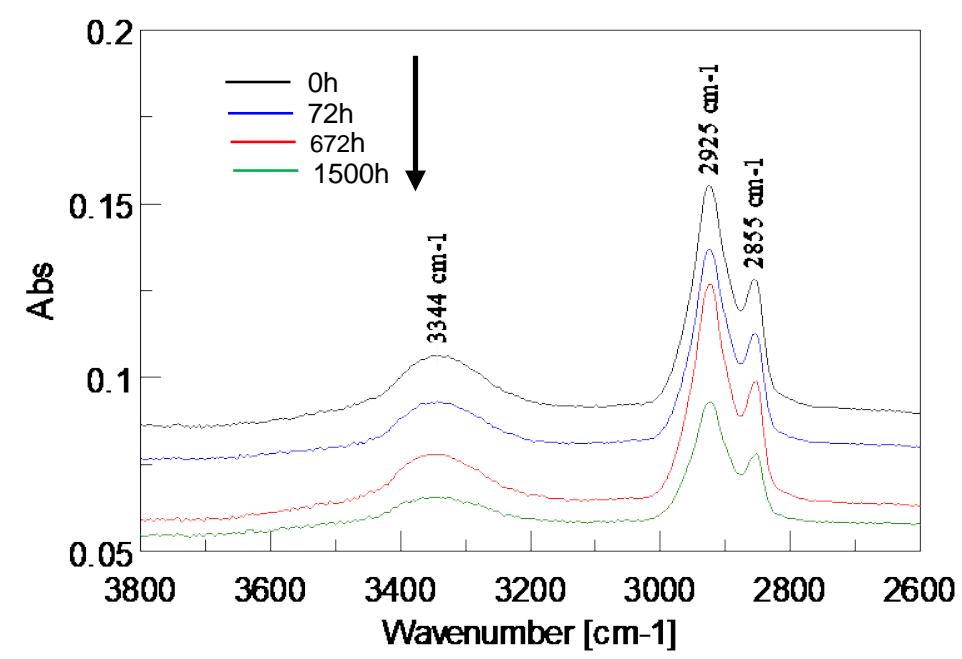

(b)

Figure 4 ATR-FTIR analysis of acrylic polyurethane coating containing bark extract and lignin stabilizer for different exposure times (a) $1800-650 \mathrm{~cm}^{-1}$ and (b) $3800-2600 \mathrm{~cm}^{-1}$

Before the detailed analysis, each spectrum was normalized at the $\mathrm{CH}$ bending frequency $\left(1451 \mathrm{~cm}^{-1}\right)$ in order to emphasize the oxidation of the polymer matrix [22]. As reported by Perrin et al. [21], $\mathrm{CH}$ bending frequency must decrease slightly due to the partial oxidation of the $\mathrm{CH}_{2}$ in the $\alpha$-NH position. Semi-quantitative measurements were carried out to comprehend the effect of different additives (Figures 5-10) on the weathering of acrylic polyurethane coating. Increase in absorption in the carbonyl region (1670-1770 $\mathrm{cm}^{-1}$ ) for acrylic polyurethane coating containing bark extract with or without lignin stabilizer suggested the formation of several oxidation photoproducts mainly the carboxylic acid (peak at $1715 \mathrm{~cm}^{-1}$ ) while a decrease in absorption was observed for the acrylic polyurethane coating stabilized with organic UV stabilizers (Figure 5). This might be due to the depletion of these photoproducts with the water spray during accelerated weathering test. Carbonyl photoproducts formed either through the direct chain scission or by the radical induced processes upon exposure to the artificial weathering conditions [24]. Significant decrease of the absorption in the region of 1605-1670 
$\mathrm{cm}^{-1}$ (H-bond and $\mathrm{C}=\mathrm{O}$ stretching of the urethane) was another noticeable phenomenon for all the three stabilized acrylic polyurethane coating as shown in Figure 6. The decrease in the absorption at $1640 \mathrm{~cm}^{-1}$ was due to the conversion of urea to urethane linkages [22]. The extent of absorption intensity loss in this region was the highest for the acrylic polyurethane coating containing bark extract and a very high loss was also observed for the acrylic polyurethane coating with bark extract and lignin stabilizer. However, relatively small change was observed for the acrylic polyurethane coating stabilized with organic UV absorbers (Figure 6). Usually a significant loss in the amide II band $\left(1530 \mathrm{~cm}^{-1}\right.$, as a result of mixed vibration involving C-N and $\mathrm{N}-\mathrm{H}$ mode) often reported due to the chain scission reaction of the urethane linkages [13]. But in the present study, a small loss in intensity of amide II band $\left(1530 \mathrm{~cm}^{-1}\right)$ was detected for all the three stabilized coating (Figure 7). The lowest loss of the urethane group was observed for the acrylic polyurethane coating containing organic UV absorber due to the presence of HALS type UV stabilizer which extends the coating durability as well as the UV absorbers lifetime [13]. The loss of the acrylate double bond (at $1407 \mathrm{~cm}^{-1}$ ) was attributed to the oxidation reactions initiated by free radicals (Figure 8) [27].

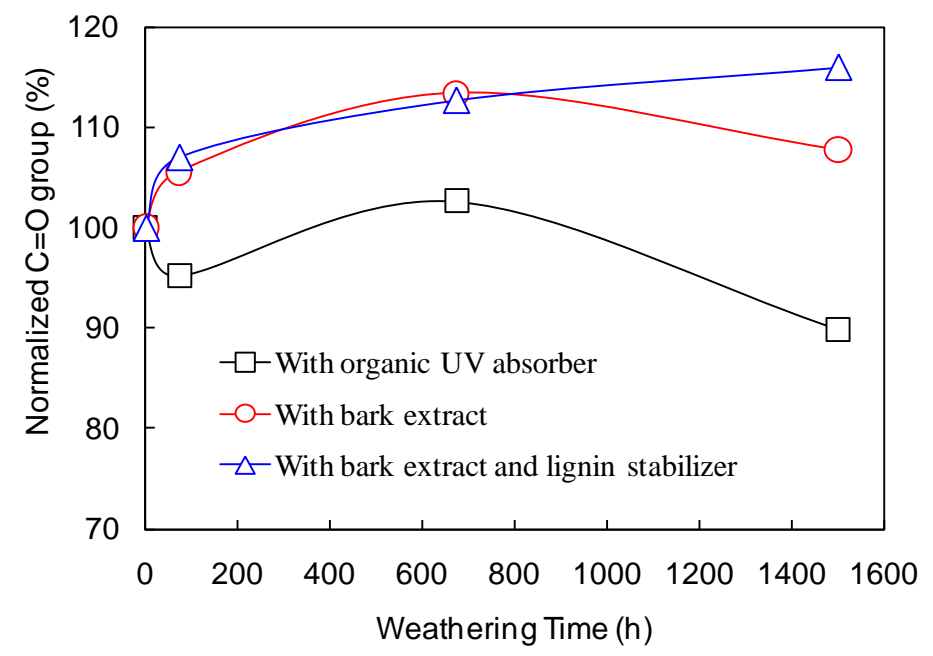

Figure 5 Buildup of oxidation products during accelerated weathering of acrylic polyurethane coatings stabilized by different additives

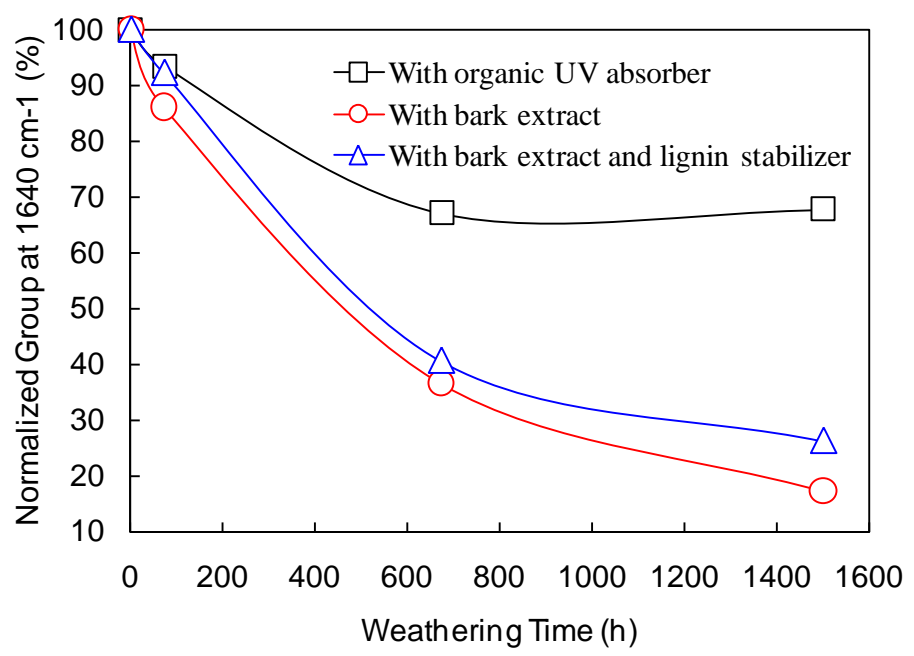


Figure 6 Diminution of $\mathrm{H}$-bond and $\mathrm{C}=\mathrm{O}$ stretching of the urethane during accelerated weathering of acrylic polyurethane coatings stabilized by different additives

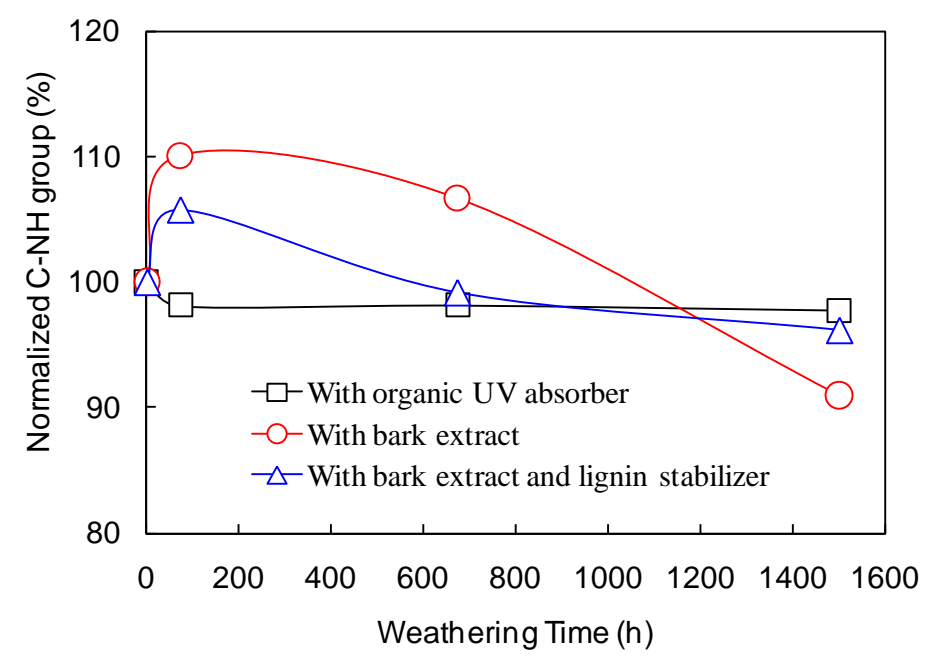

Figure 7 Change in urethane group of stabilized acrylic polyurethane coatings during weathering

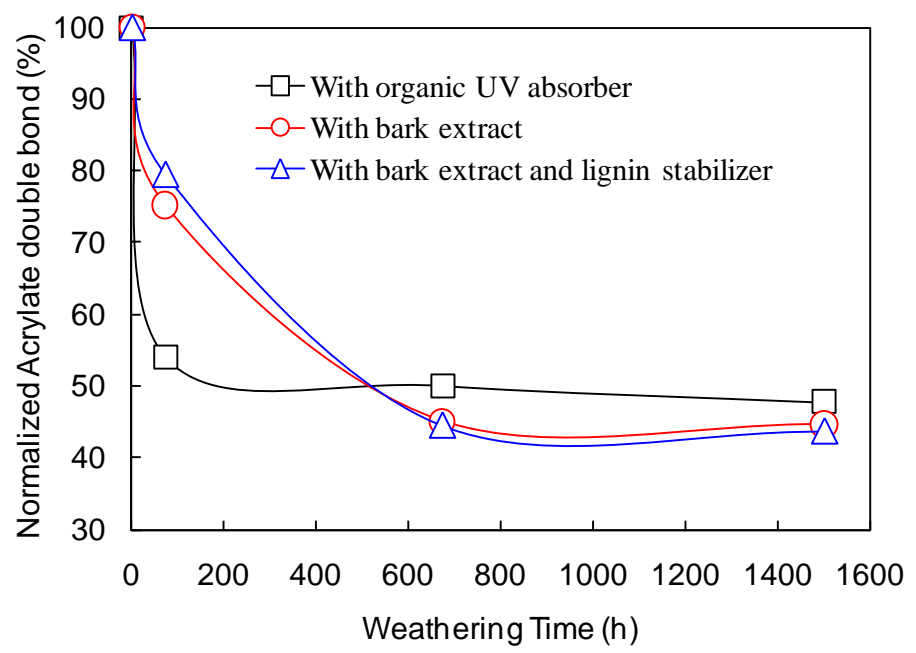

Figure 8 Loss of acrylate double bond of acrylic polyurethane coating during weathering

The asymmetric $\mathrm{CH}$ group disappeared faster than the symmetric $\mathrm{CH}$ group for the acrylic polyurethane coatings with organic UV absorbers and bark extracts. Slight increase in absorption of symmetric $\mathrm{CH}$ was noticed for the acrylic polyurethane coating containing bark extract and lignin stabilizer (Figure 9). Slight decrease in hydroxyl content $\left(3344 \mathrm{~cm}^{-1}\right)$ during initial $72 \mathrm{~h}$ of weathering was mainly due to the removal of trapped water molecules inside the coatings whereas increase in this absorption band thereafter was due to the formation of hydroxyl groups containing reaction products (Figure 10) in addition to the absorption of water in the form of moisture during accelerated weathering test. 


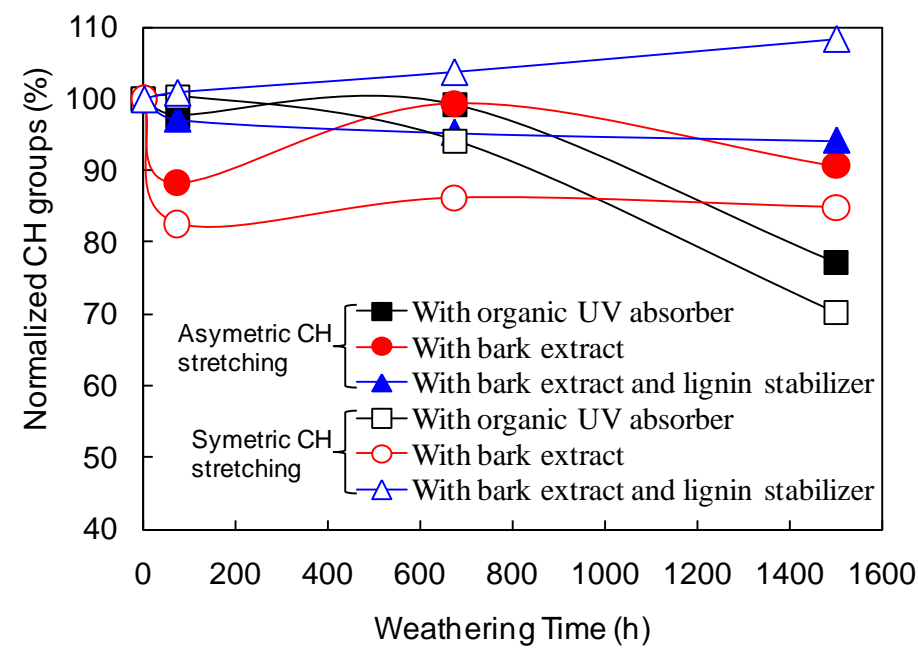

Figure 9 Changes in $\mathrm{CH}$ stretching of stabilized acrylic polyurethane coatings during accelerated weathering

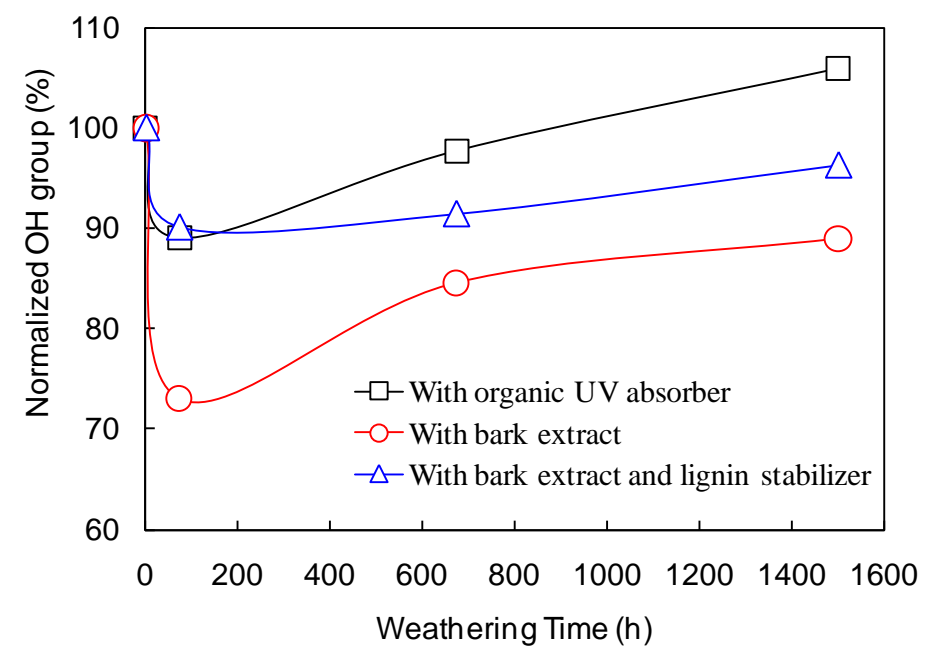

Figure 10 Changes in hydroxyl group during accelerated weathering for stabilized acrylic polyurethane coatings

From the FT-IR analyses, it seemed that the coating containing organic UV absorbers was most stabilized and should be the most durable during accelerated weathering test. However, from the accelerated weathering test results it was evident that acrylic polyurethane coating containing bark extract and lignin stabilizer was the most effective coating from the aesthetic and durability point of view. This might be explained by considering the fact that all the acrylic polyurethane coatings used in this study are transparent or semitransparent in nature. Therefore these coatings cannot prevent the sunlight to reach to the wood surface completely which eventually commences the photodegradation reaction on the wood surface. The bark extract at this stage may be very effective due to its antioxidant properties which can delay the photo oxidation reaction at the wood surface. At this stage, the UV absorber fails to perform as they can only block the harmful UV lights to reach to the wood surface. 


\section{Conclusions}

The protective characteristics of the acrylic polyurethane coating modified by different additives were studied on heat-treated jack pine using accelerated aging test and ATR-FT-IR microscopy. The results were compared with those of the commercially available coating. The performance of a new additive (bark extract), synthesized in the laboratory, was under scrutiny and this new additive proved to be very effective in preventing discoloration of heat-treated jack pine.

The color measurement results revealed a better performance of the acrylic polyurethane coating containing bark extract than the industrial coating under the accelerated weathering test conditions. The acrylic polyurethane coating also showed a similar protective characteristic as the industrial coating which should provide very high protection due to the presence of pigments (the coating is fully green) and its opaque nature. On the other hand, visual assessment demonstrated the acrylic polyurethane coating containing bark extract and lignin stabilizer as the most effective coating from the aesthetical point of view. There was a very small color change but most importantly the color change for this coating took place homogeneously. Small local degradation was observed for the acrylic polyurethane coating containing bark extract at the end of $1500 \mathrm{~h}$ of weathering. Though very small color change was observed for the industrial coating from the color measurement data, non homogeneous color change with high local degradation was observed from the visual assessment within $672 \mathrm{~h}$ of weathering.

The FT-IR spectroscopic results showed that the degradation of the acrylic polyurethane is mainly due to oxidation and loss of acrylate double bond. The crosslink scission was not significant for any stabilized acrylic polyurethane coating throughout the exposure conditions. Growth of carbonyl products was not very pronounced due to depletion of these photo products with spray water. The color change during artificial weathering was not due to coating degradation but mainly the photo-oxidation of the heat-treated jack pine since none of these coatings can completely prevent the sunlight to reach jack pine surface. The mechanism of bark extract protection of the wood surface remains unknown and further work is needed to understand this mechanism.

\section{Acknowledgements}

Authors would like to thank Fonds québécois de la recherche sur la nature et les technologies (FQRNT), Développement Économique Canada (DEC), Ministère du Développement Économique, de l'Innovation et de l'Exportation (MDEIE), Conférence Régionale des Élus du Saguenay-Lac-St-Jean (CRÉ), Université du Québec à Chicoutimi (UQAC), Fondation de l’Université du Québec à Chicoutimi (FUQAC), FPInnovation, Alberta Innovates, and industrial partners (PCI Ind., Ohlin Thermotech, Kisis Technology, and Industries ISA) for their technical and financial contributions. Authors would also like to thank Liyan Zhao of Alberta Innovates for carrying out FT-IR measurements. 


\section{References}

[1] D. Kocaefe., R. Younsi, S. Poncsak, Y. Kocaefe, Int. J. Therm. Sci. 46 (2007) 707-716.

[2] D. P. Kamdem, Pizzi A, Jermennaud A, Holz als Roh und Werkst. 60 (2002) 1-6.

[3] M. Hakkou, M. Pétrissans, P. Gérardin and A. Zoulalian, Polym. Degrad. Stab. 91 (2006) 393-397.

[4] N. Ayadi, F. Lejeune, F. Charrier, B. Charrier, A. Merlin, Holz als Roh- und Werkst. 61 (2003) 221-226.

[5] M. Deka, M Humar, G Rep, B Kričej, M Šentjurc, M Petrič, Wood Sci. Technol. 42 (2008) 5-20.

[6] W. C. Feist and D.N.-S. Hon, in: Rowell, R.M. (Ed.) The chemistry of solid wood. American Chemical Society, Washington. DC, 1984, PP. 410-451.

[7] B. Georgea, E. Suttieb, A. Merlina, X. Deglise (2005). Polym. Degrad. Stab. 88: 268-274.

[8] D.N.S Hon in D.N.S Hon and N. Shiraishi (eds.), Wood and Cellulosic Chemistry, Marcel Dekker Inc. New York, 2001, pp. 513-547.

[9] D. N. S. Hon andW. Fiest, Wood and Fibre Sci. 24(4) (1992) 448-455.

[10] D.N.S Hon, Chang S-T, Fiest W. C J. Appl. Polym. Sci. 30 (1985) 1429-1448.

[11] D. N. S. Hon and Chang S.-T. J. Polym. Sci.: Polym. Chem. 22 (1984) 2227-2241.

[12] D.N.S Hon, Chang S-T, Fiest W. C, Wood Sci. Technol. 16 (1982) 193-201.

[13] Decker C., F. Masson, R. Schwalm, Polym. Degrad. Stab. 83 (2004) 309-320.

[14] B.U. Ahn, S.K. Lee, S.K. Lee, H.M. Jeong, B.K. Kim, Prog. Org. Coat. 60 (2007) 17-23.

[15] A.C. Aznar, O.R. Pardini, J.I. Amalvy, Prog. Org. Coat. 55 (2006) 43-49.

[16] D.K. Chattopadhyay, K.V.S.N. Raju, Prog. Polym. Sci. 32 (2007) 352-418.

[17] M. Tielemans, J. P. Bleus, New Radiation-Curable Polyurethane Dispersions for Outdoor Application on Wood, Proceedings of the 5th International Wood Coatings Congress, Prague (2006).

[18] Tielemans M., J. P. Bleus, Water-Based Radiation Curable Polyurethane Dispersions as Performant Coatings for Challenging Applications, Waterborne \& High Solids Coatings "Reducing Environmental Impact” Brussels, 11-12 March 2008.

[19] J.E.P. Custodio, M.I. Eusebio, Prog. Org. Coat. 56 (2006) 59-67.

[20] C. Decker, K. Zahouily, J. Polym. Sci.: Polym. Chem. 36 (1998) 2571-2580.

[21] Perrin F.X., M. Irigoyen, E. Aragon, J.L. Vernet, Polym. Degrad. Stab. 70 (2000) 469-475.

[22] C. Merlatti, Perrin F.X., E. Aragon, A. Margaillan, Polym. Degrad. Stab. 93 (2008) 896903.

[23] Yang X. F., C.Vang, D.E. Tallman, G.P. Bierwagen, S.G. Croll, S. Rohlik, Polym. Degrad. Stab. 74 (2001) 341-351.

[24] J. Hu, X. Li, J. Gao, Q. Zhao, Prog. Org. Coat. 65 (2009) 504-509.

[25] C. Decker, F. Masson, R. Schwalm, Macromol. Mater. Eng. 288 (2003) 17-28.

[26] O.R. Pardini, J.I. Amalvy, J. Appl. Polym. Sci. 107 (2007) 1207-1214.

[27] F. Masson, C. Decker, T. Jaworek, R. Schwalm, Prog Org. Coat. 39 (2000) 115-126. 